\title{
Design of effective surface contacts on polymer composites modified with multiwalled carbon nanotubes
}

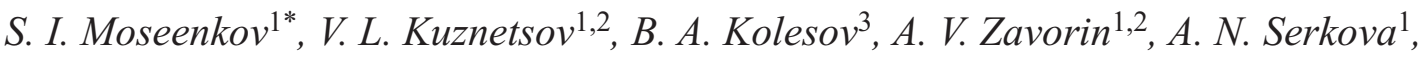 \\ N. A. Zolotarev ${ }^{2}$ \\ ${ }^{1}$ Federal Research Center Boreskov Institute of Catalysis, Lavrentiev Ave. 5, 630090 Novosibirsk, Russia \\ ${ }^{2}$ Novosibirsk State University, Pirogova str. 1, 630090 Novosibirsk, Russia \\ ${ }^{3}$ Nikolaev Institute of Inorganic Chemistry, Lavrentiev Ave. 3, 630090 Novosibirsk, Russia
}

Received 30 December 2020; accepted in revised form 12 March 2021

\begin{abstract}
In this article, we investigate the use of laser processing to create effective surface contacts on multi-wall carbon nanotube (MWCNT)/polyethylene composites. Due to the photothermal conversion effect induced by laser radiation, MWCNTs can enhance thermal destruction and removal of the polymer from the composite surface. The structure of pristine and lasermodified composites is characterized by Raman spectroscopy, optical and scanning electron microscopy. It was found that in pristine composites only a small part of MWCNTs is located directly on the surface of the film, which is associated with the high work of polymer adhesion to the nanotube surface and the surface tension forces of the polymer matrix melt. Scanning electron microscopy (SEM) and Raman scattering demonstrate that in the surface contacts formed under the action of laser radiation, the polymer matrix is removed from the near-surface layer. The presence of MWCNTs with an unchanged structure and a small amount of amorphous carbon material was confirmed by Raman spectroscopy. The conductivity of pristine and modified composites was characterized by a series of current-voltage characteristic measurements with the through-plane 4-point probe. It was found that laser treatment of the composite surface leads to an increase in the measured volume conductivity by 1-2 orders of magnitude, depending on the content of MWCNTs. At the same time, the removal of the near-surface layer of the polymer by laser treatment makes it possible to reduce the contribution of the contact resistance to the resistance of the composite measured by 2-point probe from 55-77 to $0.18-5.3 \%$ for composites with an MWCNT content of $2.5-4 \mathrm{wt} \%$.
\end{abstract}

Keywords: nanocomposites, multiwalled carbon nanotube, laser ablation, Raman characterization of composites, currentvoltage characteristic

\section{Introduction}

Due to their unique electrophysical and mechanical properties, carbon nanotubes (CNTs) are among the key components for various fields of application [1$3]$, in particular, for the development of new structural and functional materials by introducing CNTs into composites based on polymer, metal and ceramic matrices. There are many excellent monographs [4-12] providing a detailed description of physical and chemical properties of the composites modified with CNTs and other carbon nanostructures. The introduction of CNTs into composites makes it possible to improve their operational (mechanical and tribological) properties and increase thermal and electrical conductivity, thermal stability, etc. The properties of such composites are largely determined by the spatial distribution of CNTs in the bulk of the composite as well as by the nature of the interfaces between matrix material and nanotube surface. By varying the conditions for the formation of composites and the characteristics of CNTs, it is possible to change the properties of the resulting materials over 
a wide range, thus optimizing the properties of the produced composites for their practical applications. One of the application fields of conductive composites modified with CNTs is the creation of various electronic devices (including heating elements, wearable and stretchable electronics [10]) and sensors for determining deformation, bolometers, artificial sensory skin, sensors for monitoring the aging of materials and structures, and for revealing the presence of nitrogen oxides, carbon monoxide, acetone, ethanol and other gases based on the deformation of the sensitive element or changes in the state of contacts between nanotubes in thin composite films during sorption [13-16]. The creation of such electronic devices requires effective contacts with the surface of the conductive composite to reliably measure changes in characteristics of the sensitive element. To ensure the maximum sensitivity of such devices, the content of MWCNTs in the composite should be close to the theoretical percolation threshold, since in this case even a small change in the composite structure will lead to a significant change in the number of contacts between nanotubes and a change in the conductivity of the sensitive element. At the same time, the surface conductivity of composites based on polymers is, as a rule, low due to their high surface tension and immersion of nanotubes into the near-surface layers. This makes it necessary to increase the conductivity of the surface layers of composites to create effective contacts with power metal wires (conductors). In addition, due to the presence of the near-surface layer with an increased resistance in composites, the main contribution to the sensor signal will be determined by a change in the state of the contact of metal conductor with the surface of sensitive element (contact with the surface). In the case of heating elements, wearable and stretchable electronics, the flow of current through these surface contacts can generate additional heat and destroy the contacts.

In this work, we investigated the formation of surface contacts by treating polymer/MWCNT composites with a laser beam using the example of PE/ MWCNT composites.

Laser processing (mainly laser ablation) has become a powerful method in the fabrication of microstructures and nanostructures on various polymers $[17,18]$. The first report on the laser ablation of polymers was published by Cozzens and Fox in 1978 [19]. However, it is known that many polymers (polyethylene, polypropylene, thermoplastic polyurethane, etc.) are not very sensitive to laser radiation [20], which complicates their laser processing. At the same time, when the additives efficiently absorbing laser radiation are introduced into such polymers, this significantly increases the possibilities of laser modification of polymer composites due to the initiation of photothermal transformations. Metal and metal oxide additives were used as the agents initiating photothermal transformations in polymers (see the effect of introducing $\mathrm{Bi}, \mathrm{Bi}_{2} \mathrm{O}_{3}, \mathrm{Sb}_{2} \mathrm{O}_{3}$ [21, 22], ferroferric oxide $\left(\mathrm{Fe}_{3} \mathrm{O}_{4}\right)$ and zirconium oxide $\left(\mathrm{ZrO}_{2}\right)$ [23] in polyurethane). Carbon nanomaterials have also proven to be effective for local laser treatments of polymers. In particular, graphene additives have been used for controllable laser patterning of polymers [24-26]. The authors of [27] used MWCNT additives to enhance the laser patterning performance of polypropylene (PP). The three-dimensional network structure formed by CNTs can effectively improve the photothermal conversion effect of PP/CNT composites. It was demonstrated that the addition of $10 \mathrm{ppm}$ CNTs endowed PP with a clear black laser patterning performance. As the content of CNTs was increased from 10 to $200 \mathrm{ppm}$, the grayscale of the laser-induced patterns changed from black to white. An amorphous carbon material constituted the laser-induced pattern, which was confirmed by Raman spectroscopy. This paper proposes a simple and efficient method for improving the laser patterning performance of polymer materials using CNTs and provides an effective direction for practical applications of grayscale-controlled (black and white) laser-induced patterns.

In this study, a technique for laser processing of polymeric composites based on PE modified with MWCNTs was successfully developed in order to create effective contacts. The creation of reproducible contacts for connecting the conductive composites having polymer matrices is necessary for the development of various devices based on them (sensors, heating elements, wearable and stretchable electronics, etc.).

\section{Experimental}

\subsection{MWCNTs}

MWCNTs were synthesized by the catalytic pyrolysis of ethylene over a Fe-Co catalyst at $680^{\circ} \mathrm{C}[28-$ 30]. Catalyst impurities were removed by boiling MWCNTs in a solution of hydrochloric acid 
(15 wt $\%$ ) for 2 hours. Thereafter, MWCNTs were washed with distilled water until neutral. The aspect ratio of MWCNTs determined from scanning electron microscopy images was $\sim 3000$.

\subsection{Synthesis of MWCNT/PE composites}

The method of mechanical mixing in a melt was used to obtain a series of MWCNT/PE samples with a variable MWCNT content $(0.5,0.75,1.5,2.5,4,6$, $8,10 \mathrm{wt} \%$ ) in an LH3750m PE matrix (DaelimPoly). MWCNT and PE powders were premixed in a knife mill for $1 \mathrm{~min}$. The resulting mixture was homogenized twice using a Dynisco LME mixer extruder (U.S.A.) (the distance between shaft and head $200 \mathrm{mi}-$ crons, shaft and head temperatures 120 and $135^{\circ} \mathrm{C}$ ) and additionally processed on it seven times with a distance between the shaft and the head of $50 \mu \mathrm{m}$. Films of composites were obtained by hot pressing at a temperature of $140^{\circ} \mathrm{C}$ and a pressure of $10 \mathrm{MPa}$ for 5 minutes. The thickness of the films was in the range of $250-350 \mu \mathrm{m}$. The samples were designated as $\mathbf{0 . 5 M}-\mathbf{1 0 M}$, where the number indicates the mass content of MWCNTs in the composite.

\subsection{Laser modification of the composite surface}

Laser modification of the surface of the composite films was carried out using a CNC machine (CNC3040AL2, Russia) having a semiconductor laser source (GH04C05A9G Sharp) with a wavelength of $455 \mathrm{~nm}$ and a continuous power of $5 \mathrm{~W}$. Pulse-width modulation (PWM) control with a frequency of $25 \mathrm{kHz}$ was used to control the laser power. The duty cycle of the control pulses was $35 \%$. Figure 1 shows a photo of the setup and a diagram of sample processing. To prevent overheating of the sample, dry air $(11 \mathrm{l} / \mathrm{min})$ was supplied to the treatment zone through a nozzle with an inner diameter of $1.5 \mathrm{~mm}$. The cross-section of the laser beam at the focus was $\sim 50 \mu \mathrm{m}$, and the speed of the laser beam movement over the sample was $7000 \mathrm{~mm} / \mathrm{min}$. For uniform processing of the entire surface of the composite, the laser beam moved parallel to the $X$ axis with a distance between adjacent tracks $\sim 40 \mu \mathrm{m}$ (Figure 1b). To avoid burning through the sample with a decrease in the speed of the laser beam at the extreme points of movement along the $X$ axis, the beam was displaced along the $Y$ coordinate and the direction of the beam was changed outside the sample boundary. The samples were designated as $\mathbf{0 . 5 M L}-\mathbf{1 0 M L}$, where the number indicates the mass content of MWCNTs in the composite.

\subsection{Structural characterization}

The structures of pristine and laser-modified composite films were characterized using optical transmission and reflection microscopy (Micromed POLAR 1, Russia) and scanning electron microscopy (SEM, JSM6460-LV JEOL and SU8230 Hitachi, Japan). Surface reconstruction of the composites was performed by photogrammetry using the Meshroom ALICEVISION software based on a series of 15-20 SEM images obtained by varying the rotation $\left( \pm 40^{\circ}\right)$ and tilt $\left(0-40^{\circ}\right)$ of the sample relative to the microscope e-beam. Field of view SEM was $0.0012^{\circ}$.

\subsection{Raman spectra characterization}

Raman spectra of the MWCNT/PE composites were obtained on a LabRAM Horiba (Japan) single-stage spectrometer with a CCD Symphony detector (Jobin Yvon) having 2048 horizontal pixels. The laser power (the $514 \mathrm{~nm}$ line of an Ar+ laser) on the sample was typically less than $0.1 \mathrm{~mW}$. The spectral resolution was $3.0 \mathrm{~cm}^{-1}$. Single spectra were collected from regions with a cross section of about $1 \mu \mathrm{m}$. For each of the samples, a series of spectra were recorded along the chosen direction in the interval of up to $20 \mu \mathrm{m}$ with a step of $1 \mu \mathrm{m}$.

\subsection{Current-voltage characteristic measurements}

Investigation of the electrical conductivity of composites with an MWCNT content of $2.5-10 \mathrm{wt} \%$ was carried out by sequential measurement of their current-voltage characteristics (CVC) using a Keysight B2902A source meter (U.S.A.) with through-plane 4-point [31] and gold-plated $(50 \mathrm{~nm})$ electrodes with a diameter of $20 \mathrm{~mm}$ (Figure 1c, 1d). Characterization was performed in the range of applied voltages 0.001-200 V so that the current through the sample did not exceed $1 \mathrm{~mA}$ to prevent heating of the samples. Data on the current and voltage of the source and the voltage of the probe were observed for each CVC measurement. The holding at a fixed voltage before the measurement was $1 \mathrm{~s}$, the measurement time was $0.25 \mathrm{~s}$, and the number of measurement points was 10 per decade. The number of successive measurements was 4 , and the pause between them was $5 \mathrm{~min}$. The CVC of the composites containing $0.5,0.75$ and $1.5 \mathrm{wt} \%$ MWCNTs were measured 


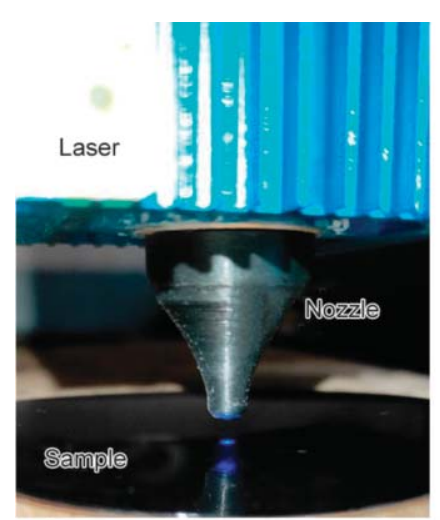

a)

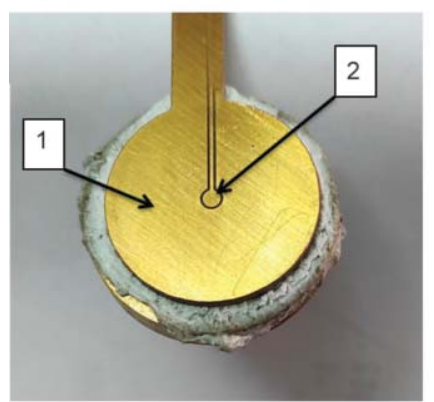

c)

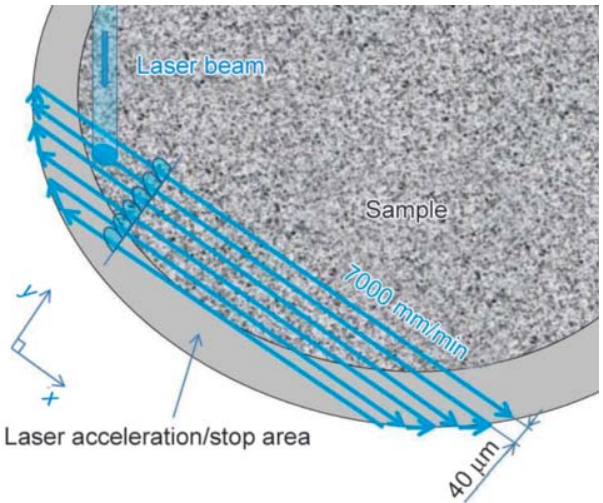

b)

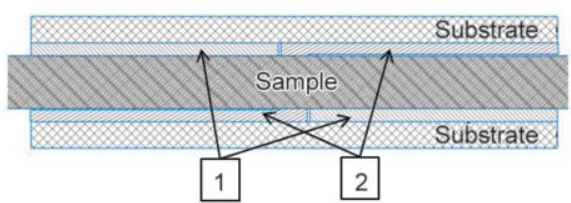

1 - Current electrode 2 - Voltage electrode

Figure 1. The experimental setup for laser treatment of composites (a). A diagram of the laser beam movement over the surface of a composite film (b). The gold-plated electrode (c) and a scheme of experimental setup (d) for throughplane 4-point conductivity measurement.

using a Keithley 6487 source meter and a Keithley 8009 fixture (U.S.A.) in the voltage range $0.001-$ $500 \mathrm{~V}$ with exposure at each voltage for $100 \mathrm{~s}$ to prevent the influence of absorption currents.

\section{Results and discussion}

\subsection{Structure of pristine and laser-modified composites}

The film structure of pristine and laser-modified composites was investigated using optical microscopy and SEM (Figure 2). It was found by transmission optical microscopy (OM) that MWCNTs are uniformly distributed in the bulk of the composites and only a few aggregates up to $5 \mu \mathrm{m}$ in size are observed (Figure 2a). At the same time, reflectance OM allows observing on the surface of pristine $6 \mathrm{M}$ composite films many dark inclusions, which are the individual aggregates of MWCNTs that protrude onto the composite surface and occupy about $5 \%$ of the surface (Figure 2b).

For laser-modified composites, light and dark stripes with a width of about $20 \mu \mathrm{m}$ are observed on the surface; the distance between them is $\sim 40 \mu \mathrm{m}$, which corresponds to the processing step (Figure 2c). The observed alternation of light and dark stripes is explained by the fact that the power of the laser beam irradiation in the cross section has a Gaussian distribution [17]. These stripes, characterized by varying degrees of radiation exposure to the composite, are formed as a result of processing polymer films on a CNC machine with the carriage movement steps comparable to the cross section of a laser beam.

A SEM study of the cross-section of pristine composites revealed that MWCNTs are uniformly distributed in the matrix volume (Figure 2d) and form a net of openwork aggregates produced during the nanotube synthesis.

SEM images of the surface of initial samples (Figure 2e) demonstrate that only a small part of MWCNT aggregates are directly located on the surface of the composite film (white arrows). The rest of the MWCNT aggregates are located in the near-surface layer of the composite (up to $10 \mathrm{~nm}$ [32]) and covered with a thin layer of polyethylene (black arrows). According to SEM data, light and dark stripes observed in optical microscopy have different surface structures (Figure 2f). Here, the dark stripes of optical microscopy look light due to the higher emission of secondary electrons from carbon nanotubes during SEM examination and vice versa.

Light stripes in optical microscopy (Figure $2 \mathrm{~g}$ and $2 \mathrm{~h})$ correspond to the regions in which the surface 

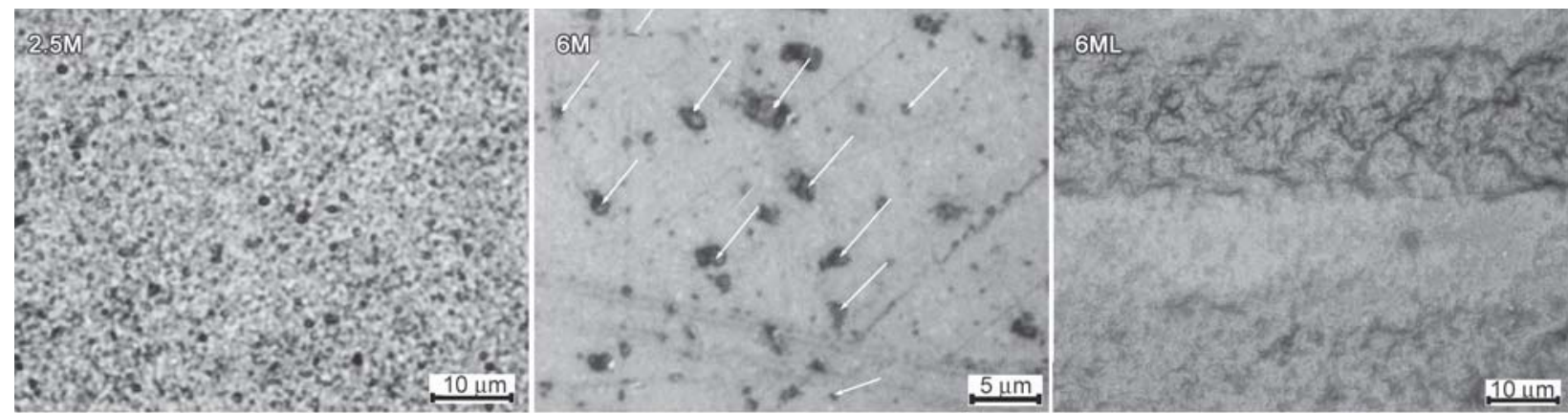

a)

b)

c)
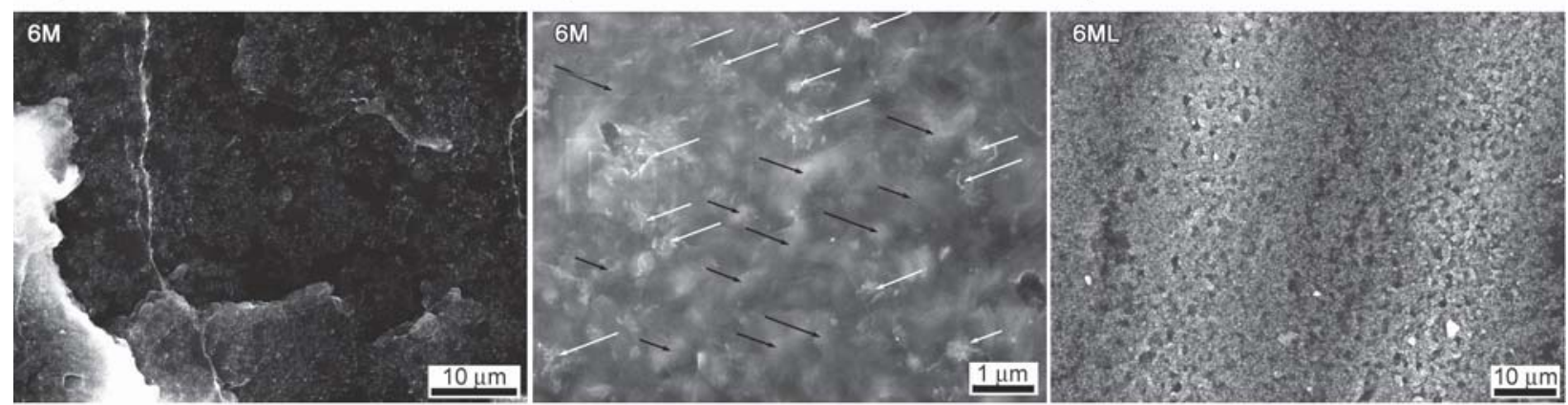

d)

e)

f)

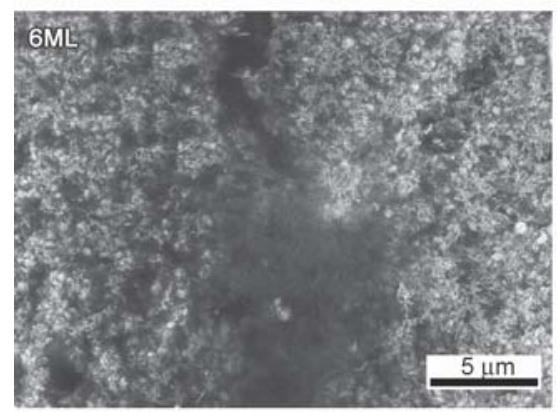

$6 \mathrm{ML}$

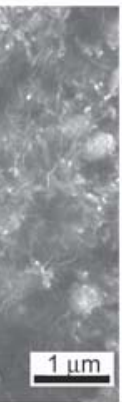

g)

h)

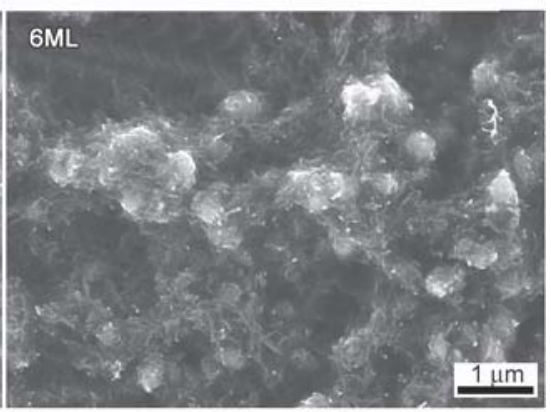

i)

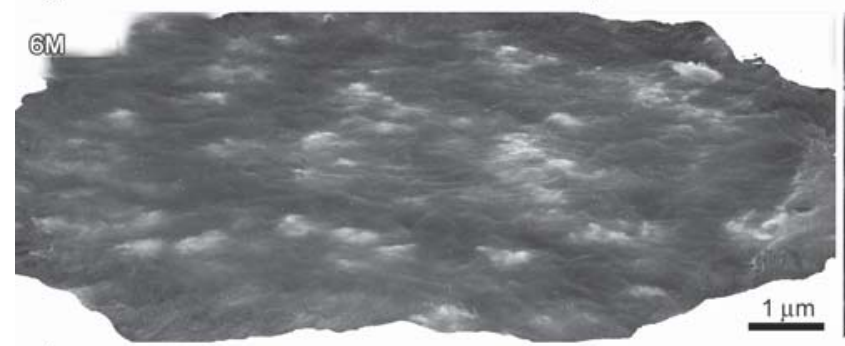

j)

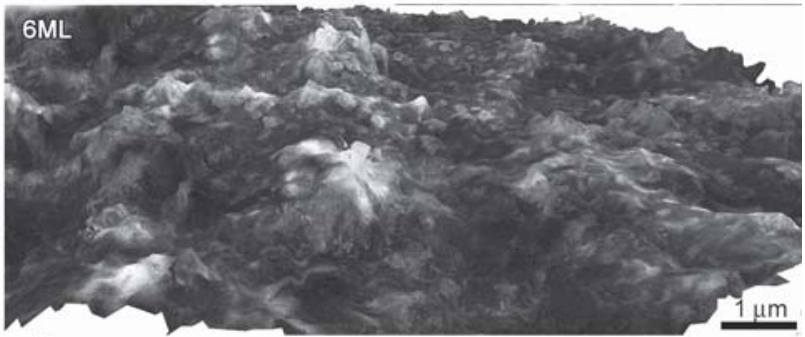

k)

Figure 2. Characterization of the composites structure by optical microscopy (OM) and SEM. (a) Transmission OM image of $2.5 \mathrm{M}$ composite; (b) and (c) reflectance OM images of pristine (6M) and laser-modified (6ML) composites, respectively (white arrows point to MWCNTs aggregates on the surface of pristine composite); (d) SEM image of cross section of the pristine 6M composite; (e) SEM image of the pristine 6M composite surface (white arrows indicate aggregates directly located on the surface of the composite film, black arrows - aggregates covered with a thin PE layer; (f) SEM image of the laser-modified 6ML composite, the reflectance OM image of which (see part 3 of this Figure) demonstrates light and dark stripes with a width of about $20 \mu \mathrm{m}$; (g, h) SEM images of light stripes in the 6ML composite observed with reflectance OM; (i) SEM image of dark stripes observed with reflectance $\mathrm{OM}$; (j) and (k) 3D reconstructions based on the sets of SEM surface images of pristine (j) and laser-modified (k) composites, respectively.

of the composite is significantly enriched with nanotubes and their aggregates in comparison with the pristine composites. The surface corresponding to the dark stripes in optical microscopy (Figure 2i) is characterized by low polymer content and is almost completely covered with openwork nanotube formations. Such a difference in the structure of the composite surface after laser treatment is associated with 
the distribution of laser radiation power having a maximum in the center of the beam and makes it possible to trace differences in the effect exerted by laser radiation of different power on the polymer surface in one experiment.

Three-dimensional surface reconstruction of the composites, which was made using 15-20 SEM images taken from different angles, showed that in the initial composite (Figure 2j) there are no individual nanotubes on the surface, and only MWCNT aggregates are observed; they protrude above the surface by $50-100 \mathrm{~nm}$ and are partially covered with a thin polyethylene layer. The surface of the dark stripe of the laser-modified composite (Figure 2k) has a more inhomogeneous 3D structure formed by MWCNT aggregates and openwork formations of individual nanotubes protruding up to $1 \mu \mathrm{m}$ above the surface.

Thus, using optical microscopy and SEM, it was found that the employed method of composite production ensures the destruction of big MWCNT aggregates. So the composites are characterized by a relatively uniform distribution of nanotubes. In a hot-pressed composite film, only a small part of the MWCNT aggregates are located directly on the surface of the composite film, while the rest of the aggregates are covered with a thin layer of polyethylene. Laser treatment removes the surface layer of the composite matrix. On the surface of the laser-modified composite, areas with an increased content of MWCNTs can be distinguished. This corresponds to a more intense effect of laser radiation, and the content of MWCNTs in such areas is higher than on the rest of the composite surface.

\subsection{Raman spectroscopy analysis of the surface structure of pristine and laser-modified composites}

In the Raman spectra of the surface of pristine and laser-modified composites, characteristic MWCNT modes (D, G, $\mathrm{D}^{\prime}$, and 2D) and characteristic vibration modes of polyethylene were observed. A typical spectrum of the MWCNT/PE composite and a typical decomposition of the spectrum into components (D $\sim 1350 \mathrm{~cm}^{-1}, \mathrm{G} \sim 1580 \mathrm{~cm}^{-1}, 2 \mathrm{D} \sim 2700 \mathrm{~cm}^{-1}$ [28] from MWCNTs and vibration modes $v-\mathrm{CH} 2800$ $3000 \mathrm{~cm}^{-1}$ from polyethylene) in the Fityk program using the Voigt function for approximating the band contours are shown in Figure 3. This decomposition does not take into account narrow and low-intensity PE modes $\left(1063 \mathrm{~cm}^{-1}-v_{\mathrm{as}}(\mathrm{C}-\mathrm{C})\right.$ trans chain, $1130 \mathrm{~cm}^{-1}-v_{\mathrm{s}}(\mathrm{C}-\mathrm{C})$ trans chain, $1296 \mathrm{~cm}^{-1}-$ $\left(\mathrm{CH}_{2}\right)$ trans chain, $1418 \mathrm{~cm}^{-1}-\delta\left(\mathrm{CH}_{2}\right)+\omega\left(\mathrm{CH}_{2}\right)$ $\mathrm{CH}_{2}$ twist). Decomposition of the spectra makes it possible to distinguish modes typical of MWCNTs and polyethylene; in addition, the decomposition provides the observation of broad characteristic peaks in the range of $1300-1600 \mathrm{~cm}^{-1}$ with maxima at $\sim 1450$ and $\sim 1520 \mathrm{~cm}^{-1}$, which were attributed to vibrations of amorphous carbon (as it was considered in [27]). However, in [28], the characteristic

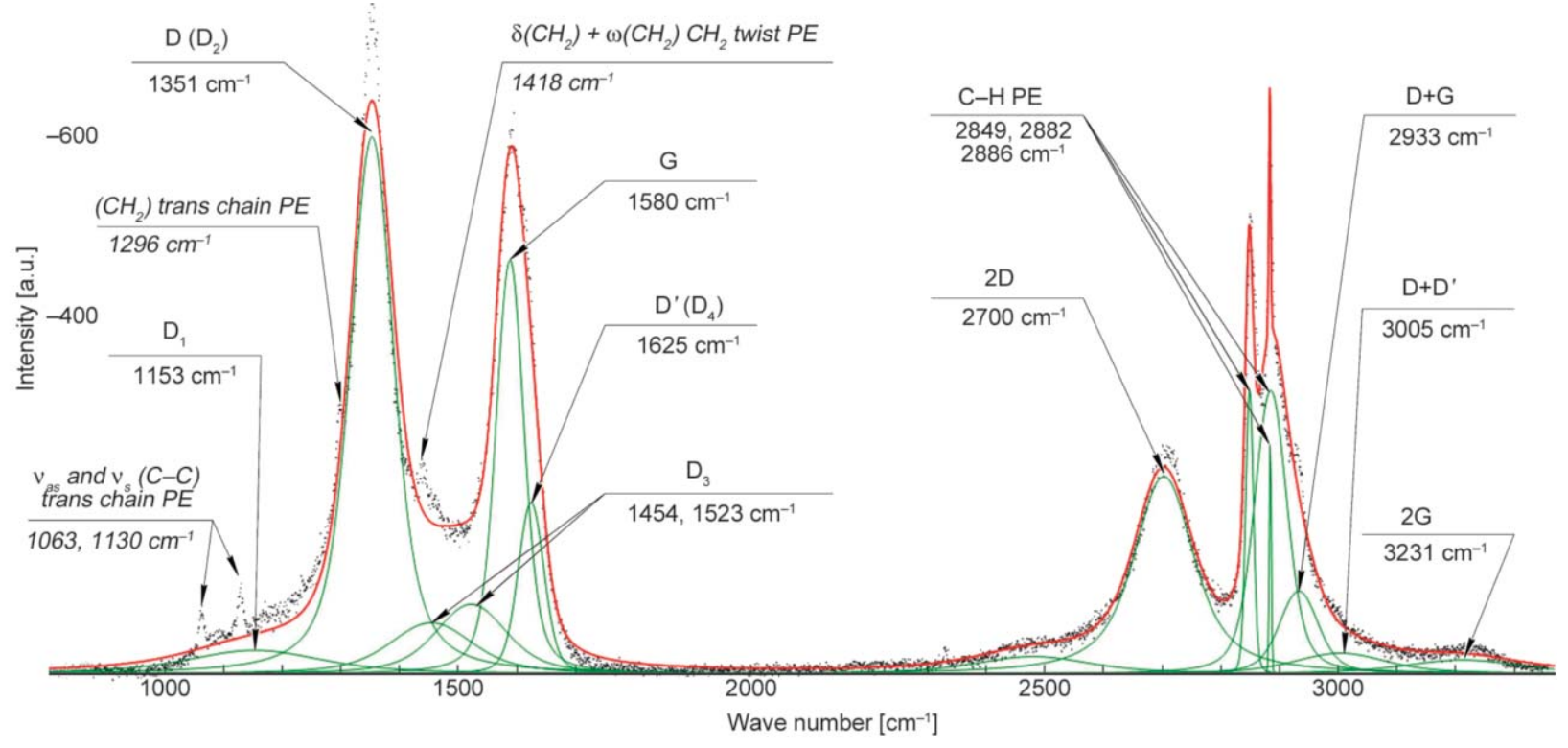

Figure 3. A typical Raman spectrum for one of the points of the pristine composite (red). Green lines represent the decomposition of the spectrum into components $\left(\mathrm{D}, \mathrm{G}, \mathrm{D}^{\prime} 2 \mathrm{D}, v \mathrm{CH}\right.$ peaks, with the release of a wide peak $\mathrm{D}_{3}$ of amorphous carbon in the region $1200-1700 \mathrm{~cm}^{-1}$ ). 
peak assigned to amorphous carbon was very wide (between 1000 and $2000 \mathrm{~cm}^{-1}$ ) and could probably correspond to several peaks of amorphous carbon. So when studying soot, coals and other disordered carbon materials, at least four bands are usually analyzed. These bands are designated as $\mathrm{D}_{1}, \mathrm{D}_{2}, \mathrm{D}_{3}$ and $\mathrm{D}_{4}$, where $\mathrm{D}_{1}$ (here $\mathrm{D}$ ) refers to graphene layer edges, $A_{1 g}$ symmetry; $D_{2}$ (here $D^{\prime}$ ) - to surface graphene layers, $E_{2 \mathrm{~g}}$ symmetry $[33,34] ; \mathrm{D}_{3}\left(\mathrm{D}^{\prime \prime}, \mathrm{A} \sim 1500 \mathrm{~cm}^{-1}\right)$ - to amorphous carbon [35-37]); and $\mathrm{D}_{4}$ (I $\sim 1200 \mathrm{~cm}^{-1}$, here $1180 \mathrm{~cm}^{-1}$ ) - to disordered graphitic lattice ( $\mathrm{A}_{1 \mathrm{~g}}$ symmetry) [38] and polyenes [37, 39].

In the decomposition of the spectra of composites in the range from 2300 to 3300 , in addition to two pronounced peaks at 2700 and $2900 \mathrm{~cm}^{-1}$ assigned to the $(2 \mathrm{D})$ overtone and $(\mathrm{G}+\mathrm{D})$ combination, respectively, very wide bands were observed at $2400\left(2 \mathrm{D}_{4}\right)$, 2940 and $3040 \mathrm{~cm}^{-1}$, which were assigned to the overtones of amorphous carbon. Narrow peaks at 2849 and $2890 \mathrm{~cm}^{-1}$ were assigned to $\mathrm{C}-\mathrm{H}$ vibrations of polyethylene $\mathrm{C}-\mathrm{H}$.

To reduce the uneven distribution of MWCNTs on the surface of the composite, the spectra were recorded sequentially at 21 points in the chosen direction with a step of $1 \mu \mathrm{m}$ and a diameter of the exciting radiation spot of about $1 \mu \mathrm{m}$ : in an arbitrary direction for the pristine composite and along light and dark stripes for laser-modified samples (Figure 5). At each point, three scans of $60 \mathrm{~s}$ duration were obtained.

Due to the uneven distribution of MWCNTs in the surface layer of pristine composite, relative intensities of the MWCNT and PE Raman peaks are antisymbatic: high intensity of MWCNT peaks corresponds to low intensity of PE peaks (Figure $4 a, 4 b$ ) and on the contrary. It is supported by the facts that polyethylene is transparent for exciting radiation $(514 \mathrm{~nm})$, while the depth of light penetration into the nanotubes is limited by their several graphenelike layers [40]. Thus, the change in intensity of the peaks corresponds to the distribution of MWCNT aggregates in the bulk of the composite film with a characteristic aggregate size of $\sim 1-2 \mu \mathrm{m}$ (Figure $4 \mathrm{c}$ ). The analysis of intensities of two phonon (2D) and $\mathrm{D}$ modes is widely used for the characterization of defectiveness and size of two-dimensional crystalline blocks in graphenes and MWCNTs [28, 41]. It should be mentioned that the incorporation of small portions of MWCNTs into PE matrix (2.5-4 mass\% loading) leads to a decrease in the intensity ratio of $2 \mathrm{D}$ and $\mathrm{D}$
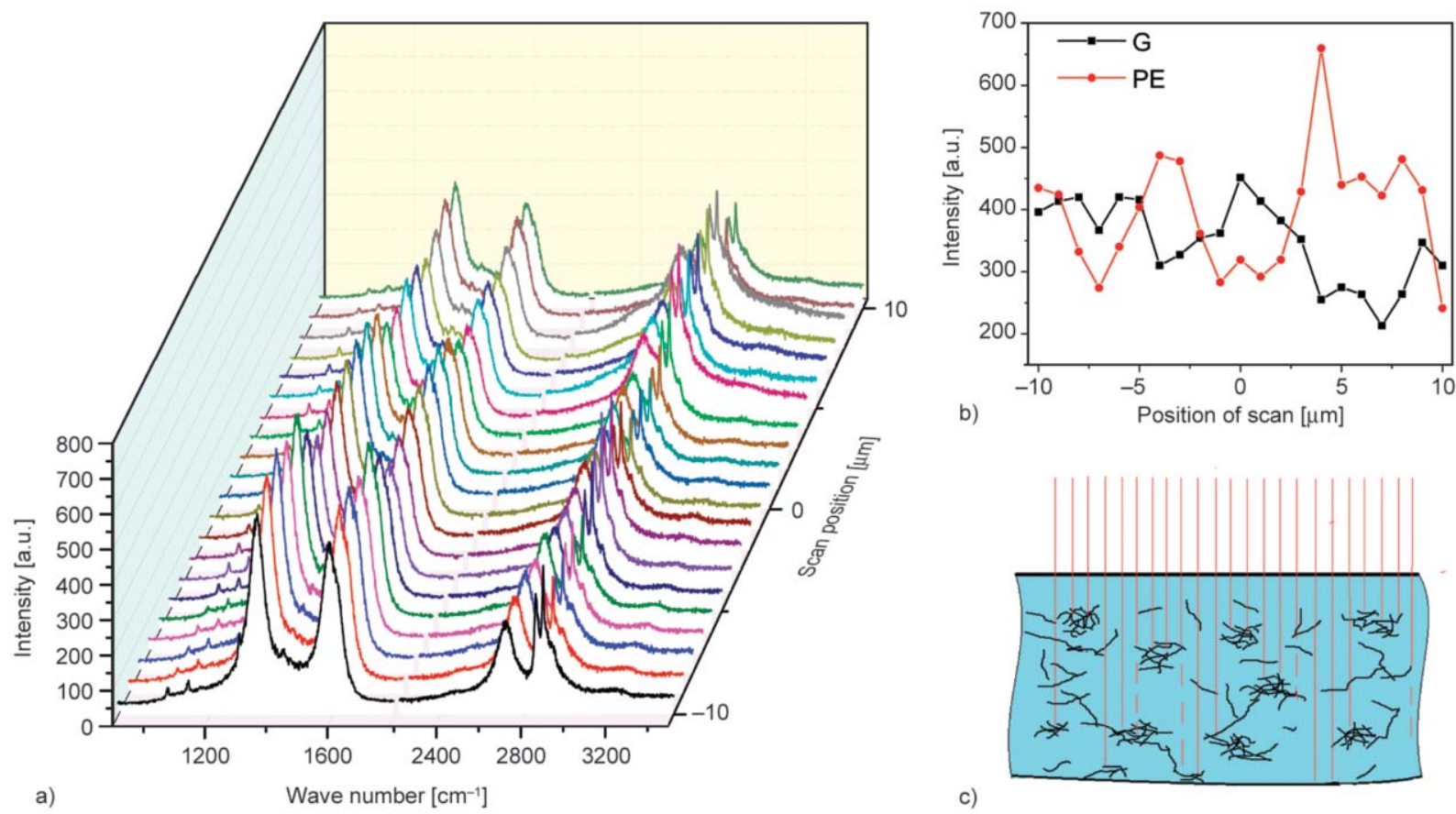

Figure 4. (a) Changes in Raman spectra depending on scan position obtained for the laser-treated composite surface. (b) Changes in the mode intensity of carbon nanotubes $\left(\mathrm{G}, 1588 \mathrm{~cm}^{-1}\right)$ and polyethylene $\left(\mathrm{PE}, 2852 \mathrm{~cm}^{-1}\right)$ along a scanning stripe with a length of $20 \mu \mathrm{m}$ (the cross-section of the exciting laser beam is $1 \mu \mathrm{m}$ ). (c) A diagram illustrating the penetration of exciting radiation into the surface layer of the composite. Due to the presence of MWCNT agglomerates, the exciting laser radiation of the spectrometer can penetrate to different depths, which causes significant fluctuations in the intensity ratio of MWCNT and PE peaks in the Raman spectra. 


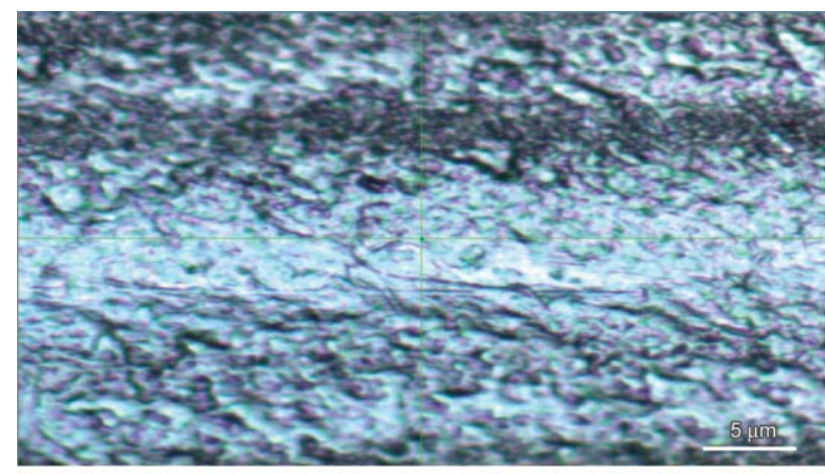

a)

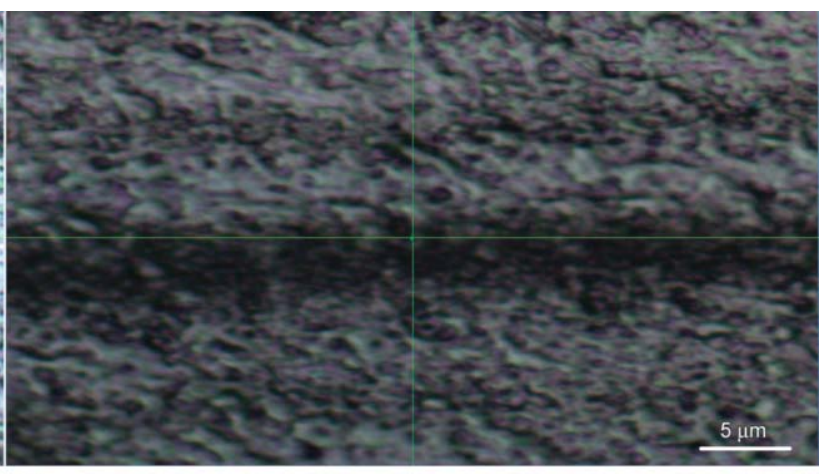

b)

Figure 5. Optical images of light (a) and dark (b) stripes on the surface of the laser-modified MWCNT/PE composite along which the successive recording of the Raman spectra was carried out.

modes $\left(I_{2 \mathrm{D}} / I_{\mathrm{D}}\right)$ (Figure 6$)$, while in composites with a higher loading of MWCNTs (6 mass $\%)$ this ratio was close to that of pristine nanotubes $(0.54 \pm 0.03)$ [42]. We believe that this phenomenon can be explained in terms of a more effective interaction of the MWCNT surface with the polymer in composites having a lower nanotube concentration. As indirect evidence one can use the data of in situ XRD study of MWCNT/PE composites [43], which demonstrates that the crystallization of PE from the melt is initiated and initially proceeds mostly on the nanotube surface. Furthermore, we have observed that the size of coherent scattering region (CSR), which corresponds to the mean size of the ordered (crystalline) domains of PE crystallites, was greater for the composites with a lower nanotube content. So one may conclude that the specific interaction of PE crystallite with the nanotube surface could be more effective in the case of composites with a lower CNT content. It can be explained in terms of a lower viscosity of polymer composites with a lower $\mathrm{CNT}$ content, which provides a

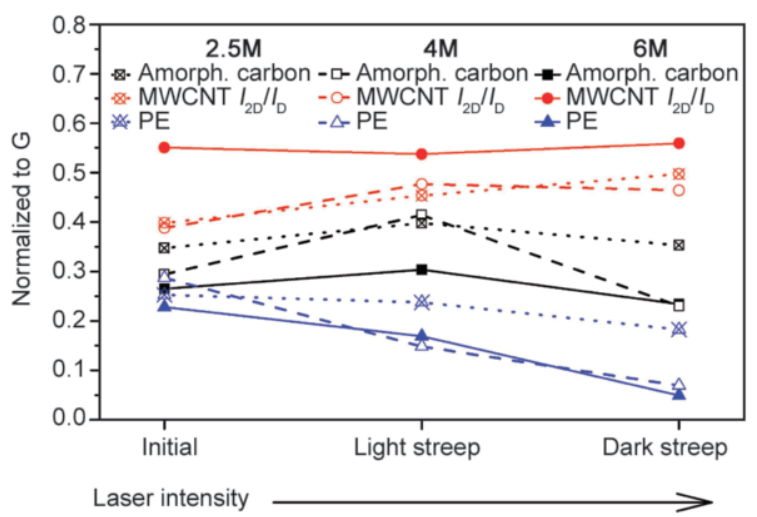

Figure 6. Changes in the intensity ratio $I_{2 \mathrm{D}} / I_{\mathrm{D}}$, amorphous carbon $\left(\mathrm{D}_{3}, 1454\right.$ and $\left.1523 \mathrm{~cm}^{-1}\right)$ and polyethylene at $2852 \mathrm{~cm}^{-1}$ normalized to the $\mathrm{G}$ band $\left(1588 \mathrm{~cm}^{-1}\right)$ in the Raman spectra for the surface of pristine and laser-modified composites. more effective interaction (in crystallographic sense) of PE crystals with the CNT surface. The structure of MWCNT-PE interfaces (with well crystallized PE blocks) may influence the intensity of two phonon Raman scattering (2D mode) and produce a relative decrease in the $I_{2 \mathrm{D}} / I_{\mathrm{D}}$ ratio for the MWCNT/PE composites with a lower CNT content.

The constancy of the MWCNT $I_{2 \mathrm{D}} / I_{\mathrm{D}}$ ratio (within an experimental error of $0.55 \pm 0.015$; for 6 mass $\%$ MWCNT loading) indicates the absence of changes in carbon nanotubes before and after laser treatment of the composite. For the composites with a lower MWCNT loading we observed an increase in the $I_{2 \mathrm{D}} / I_{\mathrm{D}}$ ratio after laser treatment.

At the same time, the proportion of PE in the light and dark bands significantly decreases (for 6 mass $\%$ MWCNT loading, by 26 and $78 \%$ compared to the pristine composite). The highest proportion of amorphous carbon was observed in the light stripes, and the lowest in the dark stripes. Due to the constancy or increase in the $I_{2 \mathrm{D}} / I_{\mathrm{D}}$ ratio for composites with a high MWCNT loading or lower loading samples, respectively, corresponding to the absence of changes in the MWCNT structure, a lower content of amorphous carbon in the dark stripe may indicate a more intense burnout of highly reactive amorphous carbon in the dark stripe (in the region of increased laser beam power).

\subsection{Current-voltage characterization of composites}

The influence of the MWCNT content and laser treatment on the electrical conductivity of the composites was determined by sequential measurements of the CVC. Successive measurements of the CVC of the composites showed that the current density through the sample increases with each subsequent 


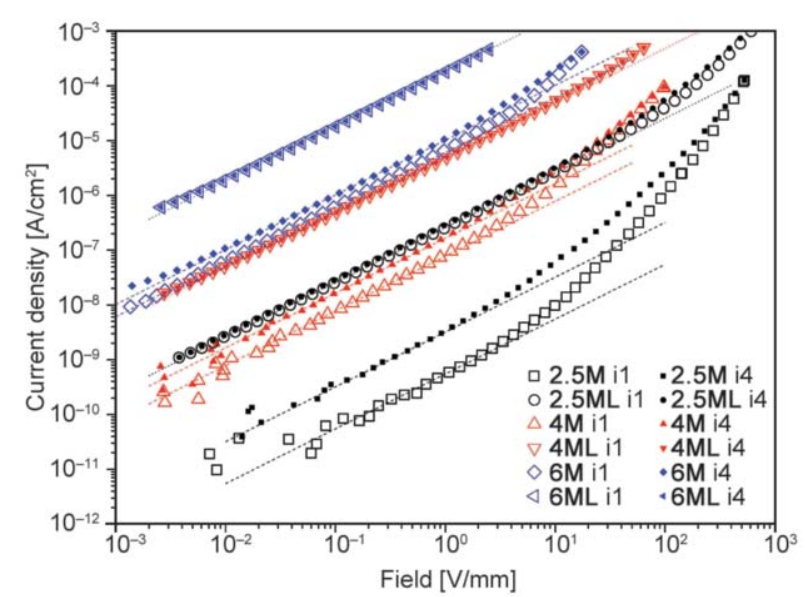

Figure 7. CVC obtained at the $1^{\text {st }}(\mathrm{i} 1)$ and $4^{\text {th }}$ (i4) sequential measurements of pristine (M series) and lasermodified (ML series) composites. Dashed lines approximation of the CVC by a linear function in the region of the ohmic dependence $j \sim E$.

CVC measurement up to the third one, and then virtually does not change.

It was found that the pristine composites containing 2.5M, 4M, and 6M MWCNTs are characterized by a nonmonotonic increase in the current density $(j)$ from the applied voltage $(E)$ (Figure 7). In the region of small applied electric fields (below $\sim 1 \mathrm{~V} / \mathrm{mm}$ ), the current density linearly depends on the electric field. A further increase in the electric field leads to a deviation from the linear dependence $j \sim E$ at the critical voltage $E_{\mathrm{cr}}$ so that $j \sim E^{\mathrm{n}}$, where $n>1$. Previously, we explained this behavior of composites by the presence of ohmic and non-ohmic contacts between individual nanotubes in them [44, 45]. In ohmic contacts, nanotubes are in direct contact with each other, whereas in non-ohmic contacts, they are separated by several polymer chains. With a sufficiently large external electric field, non-ohmic contacts are activated due to partial breakdown of the polymer matrix or displacement of the matrix from the contacts between MWCNTs; as a result, additional paths of current flow appear. In the case of partial breakdown of the matrix, $E_{\mathrm{cr}}$ of the composite decreases due to a decrease in the field required for reactivation of non-ohmic contacts between nanotubes. Such a mechanism for the formation of additional current-conducting paths is characteristic of the composites with a low MWCNT content near the percolation threshold. If the displacement (partially or completely reversible) of the polymer matrix from the contacts between nanotubes due to their heating prevails, $E_{\mathrm{cr}}$ of the composite increases due to a decrease in the resistance of the composite and a decrease in heat release.

It was found that for the pristine composites, $E_{\mathrm{cr}}$ changes after three successive measurements of the $\mathrm{CVC}$ and does not change further. For the $2.5 \mathrm{M}$ composite, Ecr decreases in the range 2.68-1.45 V/mm; for the $4 \mathbf{M}$ composite, $E_{\text {cr }}$ virtually does not change and remains within $1.14-1.17 \mathrm{~V} / \mathrm{mm}$; and for the $6 \mathbf{M}$ composite, $E_{\mathrm{cr}}$ increases in the range of $0.77-$ $0.98 \mathrm{~V} / \mathrm{mm}$. This indicates the predominance of various mechanisms for the formation of additional current-conductive paths depending on the content of MWCNTs in the composite. For the $\mathbf{2 . 5 M}$ composite, this is the partial breakdown of the polymer matrix, while for composites $\mathbf{4 M}$ and $\mathbf{6 M}$, the displacement of the polymer matrix from the contacts between MWCNTs. The appearance of additional current-conducting paths leads to an increase in the conductivity upon successive measurements of the CVC: for composites $\mathbf{2 . 5 M}, \mathbf{4 M}$ and $\mathbf{6 M}$, the current increases by a factor of 5.8, 2.1 and 1.7, respectively. Thus, the effect of the appearance of new currentconducting paths decreases with an increase in the content of MWCNTs in the composite and an increase in the number of pristine ohmic contacts.

At the same time, the CVC measurements of the composites after laser treatment showed that no increase in the current density was observed for them with successive CVC measurements. Thus, it can be concluded that the main reason for the increase in the measured current density in composites at successive CVC measurements is the formation of current-conducting paths in the near-surface layer of composite films, in which the content of individual nanotubes and their agglomerates is somewhat lower than in the bulk composite according to SEM data. In addition, according to the Raman spectroscopy data, the surface of the samples after laser treatment is characterized by an increased content of MWCNTs and amorphous carbon, which provides better electrical contact than single agglomerates of MWCNTs observed on the surface of the pristine composite. For laser-modified composites, a reproducible deviation of the dependence $j \sim E$ from the linear form is also observed at an applied field of $9.7 \mathrm{~V} / \mathrm{mm}$ for $\mathbf{2 . 5 M L}$ and $6.5 \mathrm{~V} / \mathrm{mm}$ for $4 \mathrm{ML}$, due to the reversible displacement of the polymer matrix from the contacts between MWCNTs.

Thus, taking into account the contacts between closely spaced nanotubes separated by a polymer matrix, the 

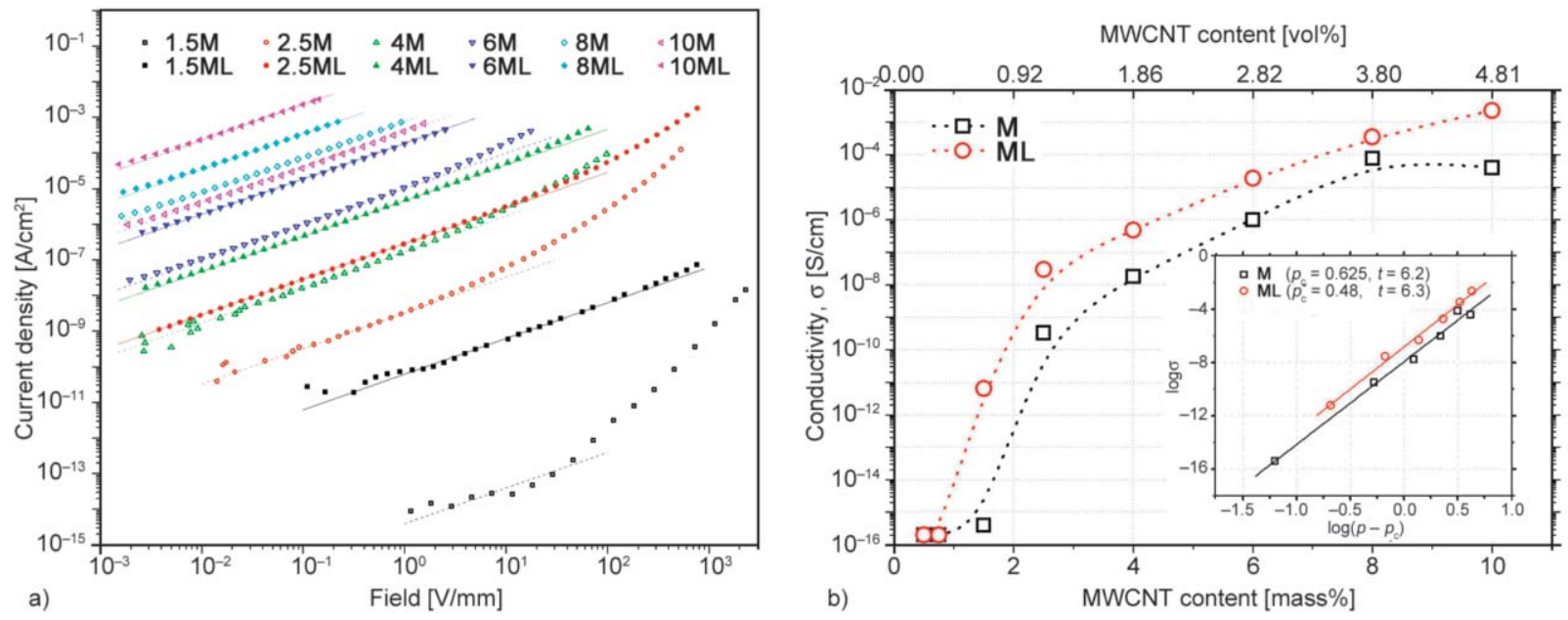

Figure 8. CVC of the pristine and laser-modified composites according to the $4^{\text {th }}$ sequential measurement (a). Dependence of the conductivity of pristine and laser-modified composites on the MWCNT content (b). The inset shows the approximation of experimental data using the dependence $\log \sigma \sim t \cdot \log \left(p-p_{\mathrm{c}}\right)\left(p_{\mathrm{c}}-\right.$ the volume content of MWCNTs).

maximum value of the conductivity of the composites was estimated from the data of the $4^{\text {th }}$ measurement of CVC (Figure 8a). Samples of composites with a MWCNT content of $0.75 \mathrm{wt} \%$ and less had a current density at the level of the ammeter sensitivity $\left(\sim 2 \cdot 10^{-15} \mathrm{~A} / \mathrm{cm}^{2}\right)$; therefore, their $\mathrm{CVC}$ are not shown, and the conductivity is taken to be $2 \cdot 10^{-16} \mathrm{~S} / \mathrm{cm}$, which corresponds to the conductivity of pure polyethylene.

One can see that for all the composites the current density increases with an increase in the content of MWCNTs at the same electric field. Also, in pristine composites, due to a decrease in the distance between nanotubes in non-ohmic contacts and a decrease in the electric field required for their activation, a decrease in the critical field $E_{\mathrm{cr}}$ is observed from $46 \mathrm{~V} / \mathrm{mm}$ for $\mathbf{1 . 5} \mathbf{M}$ to $0.77 \mathrm{~V} / \mathrm{mm}$ for $\mathbf{6 M}$. For composites $\mathbf{8 M}$ and $10 \mathrm{M}$, the linear dependence of the current on the electric field remains in the entire investigated range, which is associated with the high content of MWCNTs and many ohmic contacts between them. It was found that laser treatment of the surface of composites leads to an increase in the current at the same applied electric field and an increase in $E_{\mathrm{cr}}$. The increase in current is due to the removal of the surface layer of composites with a reduced content of MWCNTs. The greatest effect of removing the surface layer is observed for composites with a low MWCNT content. For example, for the $1.5 \mathrm{M}$ composite, the current increased more than 15000 times. Based on the CVC, the concentration dependencies of the conductivity of pristine and laser-modified composites were obtained (Figure 8b). One can see that for both the pristine and the laser-modified composites the dependence of conductivity on the MWCNT content is percolation, while for the lasermodified ML composites the conductivity is higher for each MWCNT concentration. To determine the percolation threshold value in the pristine and lasermodified composites, the experimental data were approximated using the dependence $\log \sigma \sim t \cdot \log \left(p-p_{\mathrm{c}}\right)$ (where $p_{\mathrm{c}}$ - the critical concentration of MWCNTs [vol\%], $p$ - the concentration of MWCNTs [vol\%], $\sigma$ - the conductivity of composites, and $t-$ the coefficient). It has been found that the use of laser treatment makes it possible to reduce thus calculated percolation threshold from 1.36 to 1.05 mass $\%$ MWCNT. Also, the invariability of coefficient $t$ in the range of 6.2-6.3 indicates a large contribution of the electron tunneling mechanism to the total conductivity of the composites [46] and allows assuming that under the action of laser treatment in the bulk of the composite no changes occur in the distribution of MWCNTs and the structure of contacts between them.

Based on the source current and voltage as well as the probe voltage for the $4^{\text {th }} \mathrm{CVC}$ measurement, we calculated the resistivity of the composites when measured using the 2-point $\left(R_{2}\right)$ and 4-point $\left(R_{4}\right)$ methods. This allowed us to calculate the contribution of the contact resistance to the total resistance of the composites measured by the 2-point method as $\left(1-\left(R_{4} / R_{2}\right)\right) \cdot 100 \%$ (Figure $\left.9 \mathrm{a}\right)$. It can be seen that the contribution of the contact resistance to the total measured resistance of pristine composites using the 2-point method ranges from $77 \%$ for the $\mathbf{2 . 5 M}$ to 

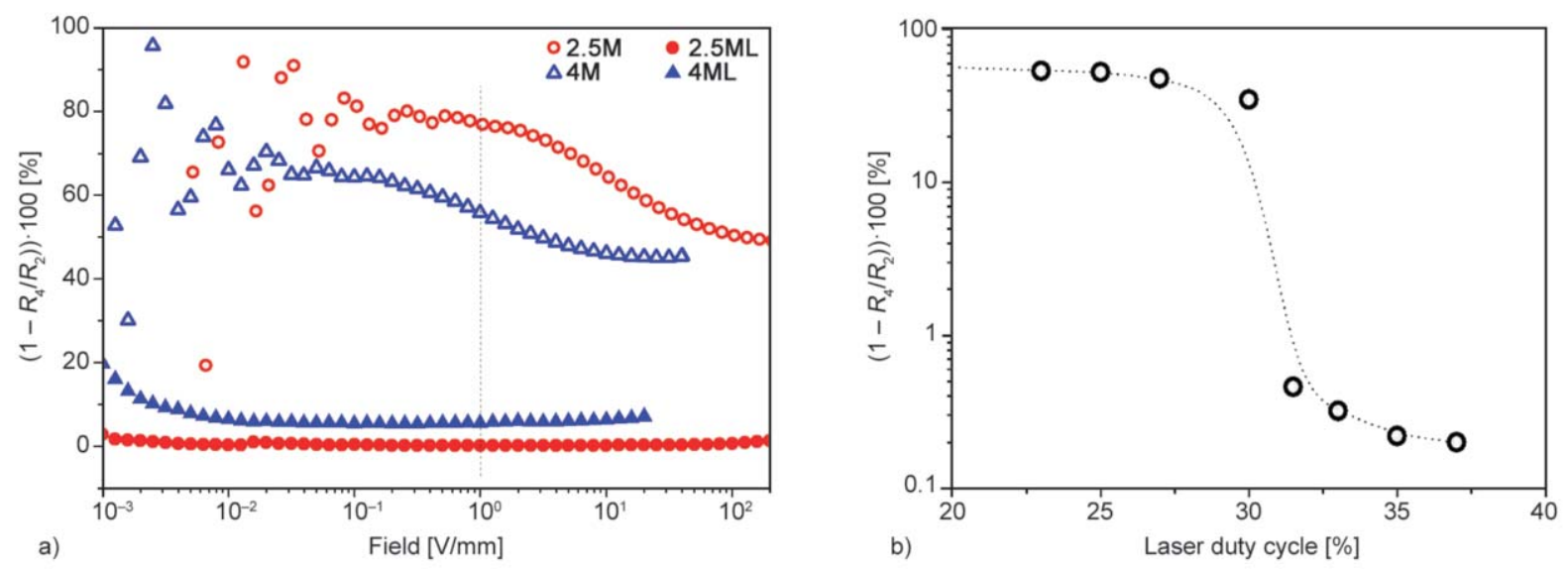

Figure 9. The contribution of the contact resistance to the total resistance of the composites measured by the 2-point method. (a) For pristine (2.5M and $4 \mathrm{M}$ ) and laser-modified (2.5ML and 4ML) composites versus the applied electric field. (b) For the $\mathbf{2 . 5 M}$ sample modified at different laser duty cycles (at a $1 \mathrm{~V} / \mathrm{mm}$ electric field). All the data for calculation were obtained during the $4^{\text {th }} \mathrm{CVC}$ measurement.

$55 \%$ for the $4 \mathrm{M}$ composite at an electric field of $1 \mathrm{~V} / \mathrm{mm}$. For laser-modified composites, the contribution of the contact resistance to the total measured resistance decreases to 0.18 and $5.3 \%$, respectively. The effect of laser duty cycle on the contribution of contact resistance to total resistance, measured by the 2-point method, was investigated for the $\mathbf{2 . 5 M}$ composite (Figure 9b). The laser power was varied by changing the pulse duty cycle in the range of 23 $37 \%$. It was found that the contribution of the contact resistance gradually decreases to $35 \%$ with an increase in the laser power to $30 \%$, and at a power of $31.5 \%$ the contribution of the contact resistance sharply decreases to $0.5 \%$. A further increase in the laser power does not significantly affect the contact resistance. This allows us to conclude that at a laser power below a certain threshold value, the heat released as a result of photothermal transformation is insufficient to completely remove the near-surface layer of the polymer, due to which some contacts contain a polymer interlayer. Almost a complete removal of the polymer in the near-surface layer of the 2.5M composite occurs at a laser duty cycle of $31.5 \%$ or more. Thus, it can be concluded that laser treatment of the surface of composites allows decreasing by more than an order of magnitude the contact resistance when connecting metal contacts to the composites.

\section{Conclusions}

In this article, we have proposed a method for obtaining effective contacts on the surface of polymer composites modified with MWCNTs, based on laser surface treatment. According to Raman spectroscopy and SEM data, during laser processing of composites, nanotubes provide the effect of photothermal transformation in the near-surface layer of the composite, thereby ensuring the removal of the polymer layer with the formation of a small amount of amorphous carbon. At the same time, the structure of MWCNTs concentrating on the surface of the contacts virtually does not change. The removal of the near-surface polymer layer reduces the contribution of the contact resistance to the total resistance of the composite measured by the 2-probe method by more than an order of magnitude and makes it possible to get rid of the nonlinear dependence of the current density on the applied field in the range up to $10 \mathrm{~V} / \mathrm{mm}$. The proposed technique can be used for the development of effective surface contacts in polymer composites modified with MWCNTs and intended for various applications.

\section{Acknowledgements}

The reported study was funded by RFBR, project number 20-33-70120. The studies were performed using the equipment of the Center of Collective Use 'National Center of Catalyst Research'.

\section{References}

[1] Dresselhaus M. S., Dresselhaus G., Charlier J. C., Hernández E.: Electronic, thermal and mechanical properties of carbon nanotubes. Philosophical Transactions of the Royal Society A, 362, 2065-2098 (2004). https://doi.org/10.1098/rsta.2004.1430

[2] Reich S., Thomsen C., Maultzsch J.: Carbon nanotubes: Basic concepts and physical properties. Wiley, Weinheim (2004). 
[3] Dresselhaus M. S., Dresselhaus G., Phaedon A.: Carbon nanotubes: Synthesis, structure, properties and applications. Springer, Berlin (2000).

[4] Mittal V.: Polymer nanotube nanocomposites: Synthesis, properties, and applications. Wiley, New York (2014).

[5] Peng H., Li Q., Chen T.: Industrial applications of carbon nanotubes. Elsevier, Amsterdam (2016). https://doi.org/10.1016/C2015-0-00493-2

[6] De Souza Gomes A.: New polymers for special applications. InTech, Rijeka (2012).

[7] Kar K. K., Pandey J. K., Rana S.: Handbook of polymer nanocomposites. Processing, performance and application Vol B. Springer, Berlin (2015).

[8] Chandrasekhar P.: Conducting polymers, fundamentals and applications: Including carbon nanotubes and graphene. Springer, Cham (2018).

[9] Tjong C. S.: Carbon nanotube reinforced composites: Metal and ceramic matrices. Wiley, Weinheim (2009).

[10] Sim K., Rao Z., Kim H-J., Thukral A., Shim H., Yu C.: Fully rubbery integrated electronics from high effective mobility intrinsically stretchable semiconductors. Science Advances, 5, eaav5749/1-eaav5749/11 (2019). https://doi.org/10.1126/sciadv.aav5749

[11] Haghi A. K., Praveen K. M., Thomas S.: Engineered carbon nanotubes and nanofibrous material: Integrating theory and technique. Apple Academic Press, New Jersey (2019).

[12] Subramanian K. R. V., George R., Rao A. C. L.: Organized networks of carbon nanotubes. CRC Press, New York (2020).

[13] Zhou M., Wang Z., Wang X.: Carbon nanotubes for sensing applications. in 'Industrial applications of carbon nanotubes' (eds.: Peng H., Li Q., Chen T.) Elsevier, Amsterdam, 129-150 (2016).

https://doi.org/10.1016/B978-0-323-41481-4.00005-8

[14] Shen H., Liu T., Qin D., Bo X., Wang L., Wang F., Yuan Q., Wagberg T., Hu G., Zhou M.: Wearable carbon nanotube devices for sensing. in 'Industrial applications of carbon nanotubes’ (eds.: Peng H., Li Q., Chen T.) Elsevier, Amsterdam, 179-199 (2016).

https://doi.org/10.1016/B978-0-323-41481-4.00007-1

[15] Majzlíková P., Sedláček J., Prášek J., Pekárek J., Svatoš V., Bannov A. G., Jašek O., Synek P., Eliáš M., Zajíčková L., Hubálek J.: Sensing properties of multiwalled carbon nanotubes grown in MW plasma torch: Electronic and electrochemical behavior, gas sensing, field emission, IR absorption. Sensors, 15, 2644-2661 (2015). https://doi.org/10.3390/s150202644

[16] Mittal M., Kumar A.: Carbon nanotube (CNT) gas sensors for emissions from fossil fuel burning. Sensors and Actuators B: Chemical, 203, 349-362 (2014). https://doi.org/10.1016/j.snb.2014.05.080

[17] Snakenborg D., Klank H., Kutter J. P.: Microstructure fabrication with a $\mathrm{CO}_{2}$ laser system. Journal of Micromechanics and Microengineering, 14, 182-189 (2004). https://doi.org/10.1088/0960-1317/14/2/003
[18] Ravi-Kumar S., Lies B., Zhang X., Lyu H., Qin H.: Laser ablation of polymers: A review. Polymer International, 68, 1391-1401 (2019).

https://doi.org/10.1002/pi.5834

[19] Cozzens R. F., Fox R. B.: Infrared laser ablation of polymers. Polymer Engineering and Science, 18, 900904 (1978).

https://doi.org/10.1002/pen.760181113

[20] Zhang J., Zhou T., Wen L., Zhao J., Zhang A.: A simple way to achieve legible and local controllable patterning for polymers based on a near-infrared pulsed laser. ACS Applied Materials and Interfaces, 8, 1977-1983 (2016). https://doi.org/10.1021/acsami.5b10243

[21] Zhong W., Cao Z., Qiu P., Wu D., Liu C., Li H., Zhu H.: Laser-marking mechanism of thermoplastic polyurethane $/ \mathrm{Bi}_{2} \mathrm{O}_{3}$ composites. ACS Applied Materials and Interfaces, 43, 24142-24149 (2015). https://doi.org/10.1021/acsami.5b07406

[22] Cheng J., Li H., Zhou J., Cao Z., Wu D., Liu C.: Influences of diantimony trioxide on laser-marking properties of thermoplastic polyurethane. Polymer Degradation and Stability, 154, 149-156 (2018).

https://doi.org/10.1016/j.polymdegradstab.2018.05.031

[23] Zhang C., Dai Y., Lu G., Cao Z., Cheng J., Wang K., Wen X., Ma W., Wu D., Liu C.: Facile fabrication of high-contrast and light-colored marking on dark thermoplastic polyurethane materials. ACS Omega, 24, 20787-20796 (2019).

https://doi.org/10.1021/acsomega.9b03232

[24] Wen L., Zhou T., Zhang J., Zhang A.: Local controllable laser patterning of polymers induced by graphene material. ACS Applied Materials and Interfaces, 41, 28077 28085 (2016).

https://doi.org/10.1021/acsami.6b09504

[25] Xie Y., Wen L., Zhang J., Zhou T.: Enhanced local controllable laser patterning of polymers induced by graphene/polystyrene composites. Materials and Design, 141, 159-169 (2018). https://doi.org/10.1016/j.matdes.2017.12.043

[26] Zhang Z., Song M., Hao J., Wu K., Li C., Hu C.: Visible light laser-induced graphene from phenolic resin: A new approach for directly writing graphene-based electrochemical devices on various substrates. Carbon, 127, 287-296 (2018).

https://doi.org/10.1016/j.carbon.2017.11.014

[27] Zhou J., Cheng J., Zhang C., Wu D., Liu C., Cao Z.: Controllable black or white laser patterning of polypropylene induced by carbon nanotubes. Materials Today Communications, 24, 100978/1-100978/9 (2020). https://doi.org/10.1016/j.mtcomm.2020.100978

[28] Kuznetsov V. L., Bokova-Sirosh S. N., Moseenkov S. I., Ishchenko A. V., Krasnikov D. V., Kazakova M. A., Romanenko A. I., Tkachev E. N., Obraztsova E. D.: Raman spectra for characterization of defective CVD multi-walled carbon nanotubes. Physica Status Solidi (B), 251, 2444-2450 (2014). https://doi.org/10.1002/pssb.201451195 
[29] Usoltseva A., Kuznetsov V., Rudina N., Moroz E., Haluska M., Roth S.: Influence of catalysts' activation on their activity and selectivity in carbon nanotubes synthesis. Physica Status Solidi (B), 244, 3920-3924 (2007).

https://doi.org/10.1002/pssb.200776143

[30] Kuznetsov V. L., Krasnikov D. V., Schmakov A. N., Elumeeva K. V.: In situ and ex situ time resolved study of multi-component $\mathrm{Fe}-\mathrm{Co}$ oxide catalyst activation during MWNT synthesis. Physica Status Solidi (B), 249, 2390-2394 (2012).

https://doi.org/10.1002/pssb.201200120

[31] Wei Q., Suga H., Ikeda I., Mukaida M., Kirihara K., Naitoh Y., Ishida T.: An accurate method to determine the through-plane electrical conductivity and to study transport properties in film samples. Organic Electronics, 38, 264-270 (2016).

https://doi.org/10.1016/j.orgel.2016.08.030

[32] Goldstein J. I., Newbury D. E., Michael J. R., Ritchie N. W. M., Scott J. H. J., Joy D. C.: Scanning electron microscopy and $\mathrm{X}$-ray microanalysis. Springer, New York (2018).

[33] Wang Y., Alsmeyer D. C., McCreery R. L.: Raman spectroscopy of carbon materials: Structural basis of observed spectra. Chemistry of Materials, 2, 557-563 (1990).

https://doi.org/10.1021/cm00011a018

[34] Ferrari A. C., Basko D. M.: Raman spectroscopy as a versatile tool for studying the properties of graphene. Nature Nanotechnology, 8, 235-246 (2013). https://doi.org/10.1038/nnano.2013.46

[35] Cuesta A., Dhamelincourt P., Laureyns J., MartínezAlonso A., Tascón J. M. D.: Raman microprobe studies on carbon materials. Carbon, 32, 1523-1532 (1994). https://doi.org/10.1016/0008-6223(94)90148-1

[36] Jawhari T., Roid A., Casado J.: Raman spectroscopic characterization of some commercially available carbon black materials. Carbon, 33, 1561-1565 (1995). https://doi.org/10.1016/0008-6223(95)00117-V

[37]Dippel B., Jander H., Heintzenberg J.: NIR FT Raman spectroscopic study of flame soot. Physical Chemistry Chemical Physics, 1, 4707-4712 (1999).

https://doi.org/10.1039/A904529E

[38] Al-Jishi R., Dresselhaus G.: Lattice-dynamical model for graphite. Physical Review B, 26, 4514-4522 (1982). https://doi.org/10.1103/PhysRevB.26.4514

[39] Dippel B., Heintzenberg J.: Soot characterization in atmospheric particles from different sources by NIR FT Raman spectroscopy. Journal of Aerosol Science, 30, S907-S908 (1999).

https://oi.org/10.1016/S0021-8502(99)80464-9
[40] Krasnikov D. V., Kuznetsov V. L., Romanenko A. I., Shmakov A. N.: Side reaction in catalytic CVD growth of carbon nanotubes: Surface pyrolysis of a hydrocarbon precursor with the formation of lateral carbon deposits. Carbon, 139, 105-117 (2018).

https://doi.org/10.1016/j.carbon.2018.06.033

[41] Martins Ferreira E. H., Moutinho M. V. O., Stavale F., Lucchese M. M., Capaz R. B., Achete C. A., Jorio A.: Evolution of the Raman spectra from single-, few-, and many-layer graphene with increasing disorder. Physical Review B, 82, 125429/1-125429/9 (2010). https://doi.org/10.1103/PhysRevB.82.125429

[42] Bokova S. N., Obraztsova E. D., Grebenyukov V. V., Elumeeva K. V., Ishchenko A. V., Kuznetsov V. L.: Raman diagnostics of multi-wall carbon nanotubes with a small wall number. Physica Status Solidi (B), 247, 2827-2830 (2010). https://doi.org/10.1002/pssb.201000237

[43] Kazakova M. A., Selyutin A. G., Semikolenova N. V., Ishchenko A. V., Moseenkov S. I., Matsko M. A., Zakharov V. A., Kuznetsov V. L.: Structure of the in situ produced polyethylene based composites modified with multi-walled carbon nanotubes: In situ synchrotron Xray diffraction and differential scanning calorimetry study. Composites Science and Technology, 167, 148154 (2018).

https://doi.org/10.1016/j.compscitech.2018.07.046

[44] Moseenkov S. I., Kuznetsov V. L., Golubtsov G. V., Zavorin A. V., Serkova A. N.: Effect of ultrasonic treatment on the properties of multiwalled carbon nanotubes - polymethylmethacrylate composites: Effect of applied voltage and pressure on conductivity of the composites. Express Polymer Letters, 13, 1057-1070 (2019). https://doi.org/10.3144/expresspolymlett.2019.92

[45] Moseenkov S. I., Zavorin A. V., Ishchenko A. V., Serkova A. N., Selyutin A. G., Kuznetsov V. L.: Using currentvoltage characteristics to control the structure of contacts in polyethylene based composites modified by multiwalled carbon nanotubes. Journal of Structural Chemistry, 61, 628-639 (2020). https://doi.org/10.1134/S0022476620040174

[46] Balberg I., Binenbaum N.: Cluster structure and conductivity of three-dimensional continuum systems. Physical Review A, 31, 1222-1225 (1985). https://doi.org/10.1103/PhysRevA.31.1222 